reactor operation. Accordingly, it has been decided to build at Harwell, in addition to the zero energy fast fission reactor (which has now been operating for some two months), a small research reactor operating at a very high intensity to permit the necessary experimental studies to be carried out. The new pile will also make it possible to produce certain radioactive isotopes such as cobalt-60, which cannot be made with sufficient specific activity in BEPO. The use of heavy water as a moderator enables the required facilities to be obtained at a lower capital cost than would be possible with a graphite-moderated system. The reactor will use as fuel highly enriched uranium which will be supplied from the diffusion plant operated by the Atomic Energy Industrial Group at Capenhurst. General design of the new pile is being undertaken by the Atomic Energy Research Establishment, while detailed design and provision of reactor components will be a responsibility of Messrs. Head Wrightson Processes. The Ministry of Works is undertaking civil and general mechanical work in connexion with site services, building and. installation.

\section{The Organization of Pure and Applied Science}

The address on pure and applied science and their appropriate forms of organization, which Prof. M. Polanyi delivered last Juy in Hamburg at the Congress on Science and Freedom (see Nature, 172 , 445 ; 1953), has now been published as Occasional Pamphlet No. 14 by the Society for Freedom in Science (pp. 13, 1953; 1s. 3d.; from the Society at the Department of Zoology, University of Oxford). Empirical science, he points out, is based on observations, while technology is a collection of inventions. Not all empirical knowledge forms part of science, and only a part of technology is applied science. While empirical technology is necessarily unsystematic, it can be an important source of information worthy of scientific study. Such technically justified science, like systematic technology, founded on an application of science, forms a field of study lying between pure science and pure technology. The principles for the proper organization of research in pure science are determined by the distinctive characteristics of pure science; and since all real scientific discovery must show originality, expanding the system of science in an unexpected way, scientific discovery is an essentially independent task. Scientific resenrch nevertheless must rely for financial support on public subsidies, and for the effective advancement of science as a whole the individual independent research tasks must be co-ordinated through $a_{0}$ spontaneous system operating under the control of scientific opinion. Within this framework the function of the public authorities is to supply the scientist whose work is appreciated by public opinion with the means for pursuing his own interests in science, giving preference to those who have the greater prestige in science. The study of technologically justified branches of science should be cultivated under the auspices, and at the expense, of special interests served by the inquiry, but without drawing away too much talent from the pursuit of scientific inquiries of universal interest. The study of systematic technology should be organized like the advancement of pure science. Finally, Prof. Polanyi urges that, when the State establishes institutions for the cultivation of science, it recognizes a realm of independent ideas and independent men. It admits that the requirements of this realm demand con. sideration equally with the political and material interests of the society guarded by the State, and by implication the State is committed to foster the advancement of science under the guidance of its own accepted scientific leaders.

\section{Corrosion Prevention and Control}

THE appearance in March of the first number of a new journal, Corrosion Prevention and Control: Engineering-Equipment-Technology (1, No. 1, March 1954 ; published from Holland House, 140 Cromwell Road, London, S.W.7; 30 s. or 5 dollars for one year, and 75s. or 12.50 dollars for three years), is in line with the increasing interest being shown in the subject of corrosion prevention. This interest has already found expression in the formation in 1951, by the Society of Chemical Industry, of a Corrosion Group to encourage the presentation and publication of original papers and of reviews. The new journal is, however, the first in Britain to be devoted exclusively to the subject of corrosion, the aim being to present accounts of new developments in a form suitable for rapid appraisal by engineers, chemists and metallurgists who are concerned with the practical application of corrosion knowledge. In the first number this object has certainly been achieved. The editorial comment is of a high standard. Articles refer to cathodic protection, zirconium, metal pre-treatment, protection by paints and resistant plastics. Under the heading "Technical Review" are listed forty-one items relating to progress in corrosion prevention, while abstracts of twenty-three corrosion patents are given in a separate section. With two exceptions, all the articles are anonymous. The sixty-four pages in the first number include ten and a half pages of advertisements. It would be preferable, however, to paginate all advertisement matter separately. The publication of future issues of the new joumal will be awaited with interest.

\section{Collected Reprints of the National Institute of Oceanography}

THE National Institute of Oceanography in Great Britain, following the example of the oceanographic institutions of the United States, has issued the first volume of the "Collected Reprints" of many of the publications of its staff (pp. vii +61, December 1953; from the Institute, Wormley, Godalming, Surrey). The papers in question were originally published during the years 1949-53 inclusive, and are on many branches of both physical and biological oceano. graphy, including the design and operation of instruments of observation. In accordance with the deliberate policy of the Institute, these papers appeared in a wide range of journals, few of which are of a specialized oceanographic character and some of which cater for the general reader. The alternative would have been for the Institute to publish its own journal, and indeed it does continue to publish the "Discovery Reports", which deal with work based mainly on the observations and collections of the former Discovery Committee, or closely related to. that work. But the method of publication chosen for the newer work brings this to the notice of readers outside the field of oceanography, and gives the staff of the Institute the benefit of criticism from those using similar techniques. For oceanography is only the application of the various basic sciences to the acquisition of knowledge of the oceans. Of the papers written for the general reader, a good pro- 